\title{
The Essential Role of Cross-national Research in Assessing Theories of Crime: Illustrations from Modern Control Theory
}

\author{
Michael R. Gottfredson ${ }^{1}$ (]
}

Received: 4 December 2020 / Accepted: 14 December 2020 / Published online: 23 January 2021

(c) The Author(s) 2021

\begin{abstract}
Contemporary research from around the world provides a body of consistent findings, making it an indispensable tool for the evaluation of crime theory. To be valid, general theories of crime must now be able to accommodate the results of this cross-national research. Modern Control Theory is used as an illustration for conceptualizing this body of research. Research from three critical areas relevant to general theories of crime are used to illustrate the critical nature of this research: (1) results from self-report surveys of offending and victimization; (2) research on the lack of effectiveness of criminal justice sanctions in affecting rates of crime and interpersonal violence; and (3) prevention research that is focused both on early childhood and on the settings in which much crime occurs. Each is consistent with the expectations of Modern Control Theory (Gottfredson and Hirschi in Modern control theory and the limits of criminal justice, Oxford University Press, New York, 2019) and each demands the attention of any general theory purporting to explain crime and interpersonal violence.
\end{abstract}

Keywords Control theory $\cdot$ Self-control $\cdot$ Social control $\cdot$ Age and crime $\cdot$ Prevention $\cdot$ Criminal justice sanctions

\section{Introduction}

There can be no doubt that the internationalization of criminology is an important aspect of modern, scientific criminology. Criminology has always rested fundamentally on contributions from scholars around the world, of course. Theoretical criminology certainly has strong international, interdisciplinary roots, roots that continue to provide fundamental insights for contemporary theory (Paternoster and Fisher 2018; Valasik 2014). ${ }^{1}$ Today, it is simply not possible to consider theoretical issues in criminology absent an appreciation of empirical contributions from scholars throughout the world (Bennett 2004; Gottfredson 2018a, b; Tonry 2014). The contributions to knowledge from empirical studies of delinquency, crime, and criminal justice globally are vast,

\footnotetext{
1 As just one example, Modern Control Theory (Gottfredson and Hirschi 2019; Gottfredson 2021), rests fundamentally on the insights of Beccaria (1764), Quetelet (1842), and Bentham (1798), among others.
}

Michael R. Gottfredson

gottfred@uci.edu

1 University of California, Irvine, USA such that contemporary explanations for crime from any source are clearly incomplete if not informed by crossnational research. As Liu has noted, the diversity of cultures, peoples, settings, and justice systems provided by cross-national research provides an essential methodology for theoretical development: “...diversity presents difficulties, but also advantages and opportunities", and this diversity is not an impediment to scientific work; rather it presents "...indispensable opportunities to develop modern criminology" (2009, p. 5). Vazsonyi aptly argued nearly two decades ago that "...cross-national comparative criminology is not a particular branch or subdiscipline of criminology; it is criminology itself" (2003, p. 204).

From the point of view of control theory, we have argued that to be valid, ".... a general theory of crime and delinquency must be applicable to diverse settings, people and times, including differing societies, populations, and cultures" (Gottfredson and Hirschi 1990, pp. 169-179). Furthermore, not only must a general theory be able to account for correlates about crime and delinquency in diverse settings and times, but the principal causal assertions also must find broad empirical support from research methods that are consistent with its logic and internal structure (Gottfredson 
$2018 \mathrm{a}, \mathrm{b}) .^{2}$ It is clear that contemporary measurement studies of violence, crime and victimization have shown there are important commonalities about crime among many countries, patterns that simply do not allow scientific criminology to be anything less than international. And, of course, basic causal analysis presupposes that even appreciating the critical importance of location, geography, culture, and legal/political system in the explanation of crime and victimization requires a theory of crime that explains and specifies the commonalities of crime and justice internationally that do not depend on these causes (Gottfredson 2018a).

Given that it is not possible to consider the present field of scientific criminology in anything less than an international perspective, the focus of this essay must be restricted and modest: we can briefly illustrate the significance of crossnational research by indicating the impact it has for Modern Control Theory, one aspiring general theory of crime (Gottfredson and Hirschi 2019). We can do so by discussing the relevance of some cross-national research to Modern Control Theory in three areas: (1) some major correlates of interpersonal violence, crime and victimization as shown in sample surveys; (2) the consistency with which it is difficult to find evidence consistent with a claim of substantial effectiveness for criminal justice sanctions on crime rates in crossnational research; and (3) the evidence about advantages of prevention approaches to the reduction of interpersonal violence and victimization, cross-nationally. Even at that, our consideration for this essay must necessarily be illustrative and limited given the enormous scope and significance of cross-national work in each of these areas.

\section{Illustrations from Modern Control Theory ${ }^{3}$}

We have argued that the scope of a theory is one essential element in judging a scientific theory's value (along with such dimensions as validity, parsimony, and internal consistency) and therefore that testing our theories against the high-quality research throughout the world is essential for

\footnotetext{
2 Although not adequately considered in this essay, it needs be said that cross-national research has demonstrated important advantages for politically or culturally distinct traditions of justice and social control, with findings that can spawn improvements elsewhere (e.g., Huff and Killias 2013).

3 This section draws on Gottfredson and Hirschi (2019), esp. Chap. 11, Gottfredson (2018a, 2021). There has been an important literature suggesting many of these same points from other theoretical points of view, e.g., Agnew (2015), Bennett (2004), Liu (2009), Messner (2015), Sampson (2015), Tonry (2014), Vazsonyi (2003), Wikström et al. $(2012,2018)$.
}

criminology's search for explanation (Gottfredson 2018a). ${ }^{4}$ A brief outline of our general theory of crime and victimization, what we refer to as Modern Control Theory (Gottfredson and Hirschi 2019), can help conceptualize the impact of what may seem to be somewhat disparate findings and suggest why future contributions from cross-national research are vital to inform theoretical criminology.

Figure 1 presents a simple schematic of essential elements of Modern Control Theory (Gottfredson and Hirschi 2019, Chap. 12) useful for thinking about how some methods and findings from cross-national criminology relate to the theory. Although there are differences between our theory and other versions of control theory and other uses of some of these terms (especially the concepts of self-control and crime), these key elements, collectively differentiate our perspective from many other theories of crime, and are useful as a context to consider the connections between Modern Control Theory and cross-national research on crime and justice. A depicted by Fig. 1, our perspective begins with a common, but distinctive, disciplinary-free animating assumption of human nature (the pursuit of self-interest, guided by rationality), an assumption that readily provides for a cross-disciplinary focus on problem behaviors; it includes a developmental focus beginning with early childhood; it acknowledges the now rather vast accumulated evidence about the importance of both self-control and informal social controls for understanding interpersonal victimization, crime and violence; it similarly acknowledges the large literature demonstrating the importance of characteristics of events or settings as causes of crime; it stipulates the vast evidence about the necessity of including a direct age effect in theories of crime; and it embraces the accumulating evidence from policy-related research about the comparative benefits of prevention early in life and attention to the event properties of crimes relevant to informal prevention, in contrast to policies focused on the criminal justice system. Each of these elements finds considerable support in cross-national criminology, research that has examined these elements on the basis of many societies, types of crime (from interpersonal violence to fraud, bullying and white-collar crime), differing demographic groups, and via very wide range of methods. Taken together, these elements of Modern Control Theory provide a parsimonious, logically consistent, empirically grounded general theory. The extent to which these assertions have validity, this support challenges substantially other theories of crime and victimization, theories with markedly different assumptions and concepts for these elements.

\footnotetext{
${ }^{4}$ For an earlier argument stressing the importance of scope for assessing the value of crime theories in cross-national work, see Bennett 1980 .
} 
Fig. 1 The five essential elements of modern control theory. Source Adapted from Gottfredson $(2021)$

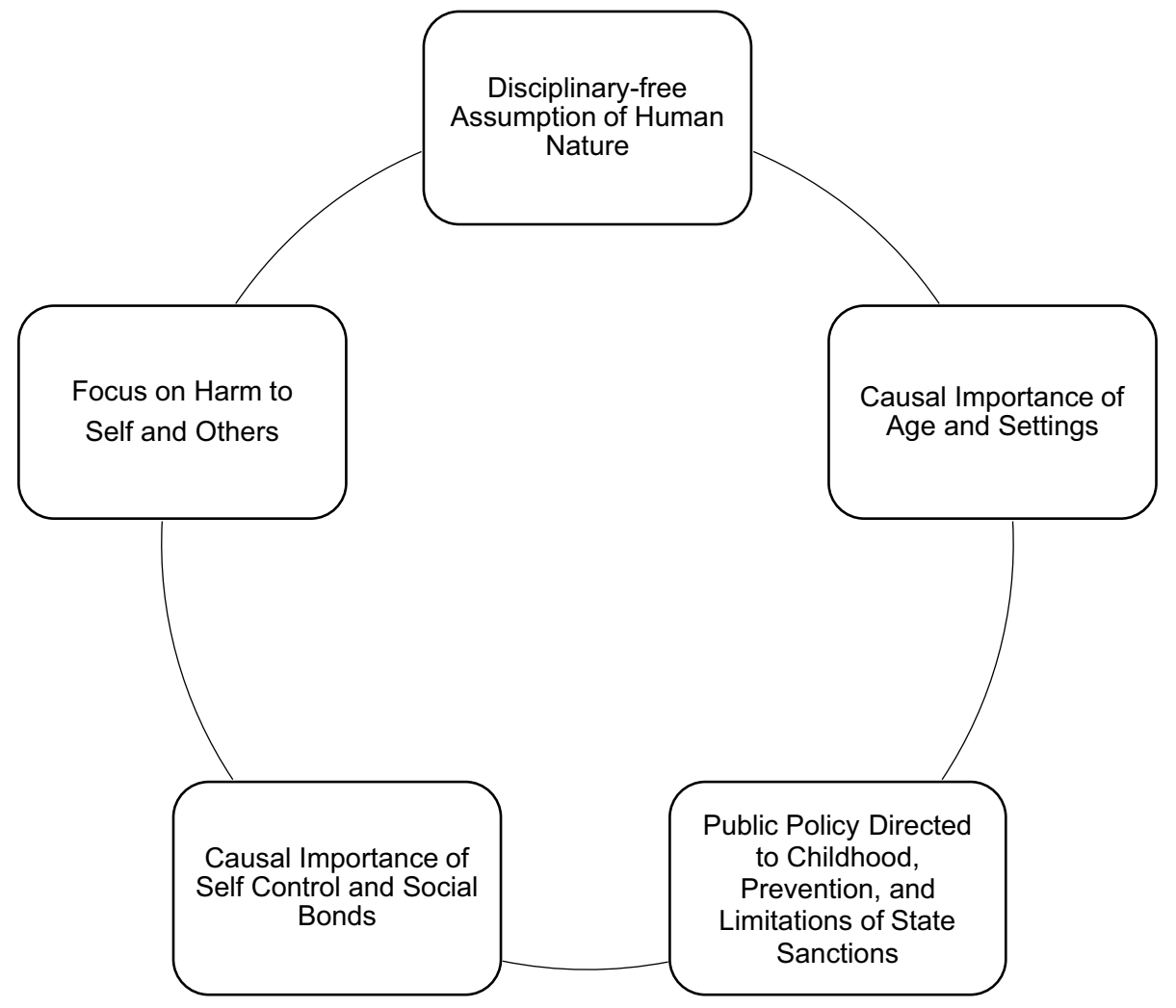

The element, or animating assumption, for Modern Control Theory that may be of most consequence for a scientific cross-national criminology concerns the very issue of what the dependent variable for our science should be: for control theory, the dependent variable is not a legal definition of crime or victimization, but rather problem behaviors that harm self and others. ${ }^{5}$ It therefore rests on a general, disciplinary- free definition of the dependent variable, one that is not synonymous with crimes as that term is often used in criminology or strictly with legal definitions for crime and delinquency. Our focus is on acts that provide near-term benefits to the actor, but which can carry subsequent negative consequences. Such a definition permits inclusion of most behaviors that are violations of delinquency statutes and criminal laws (but not all), as well as many behaviors that cause harm but which are not violations of criminal laws, thus enabling application of the theory's principles broadly across cultures, political systems, traditions of informal social control and the like.

\footnotetext{
${ }^{5}$ For a detailed discussion of the rationale for this principal assumption, see Gottfredson and Hirschi 2019, Ch. 2; Gottfredson 2011).

${ }^{6}$ Our concept of self-control was derived from the properties of crime and related problem behaviors. It has occasionally been characterized in some quite misleading ways. Our concept differs fundamentally from some other definitions, such as those imported from psychology and biosocial criminology (see, e.g., Burt et al. 2006,
}

The growing recognition of the critical role of self-control for life chances and success results in a strong claim for concepts of self and social control that are disciplinary- and culturally free. The definition of low self-control used in our general theory is fully applicable to a wide range of problem behaviors studied in criminology, education, public health, economics, and psychology ${ }^{6}$ : as we said in the initial presentation of the theory, "It is the tendency of individuals to pursue short-term gratification without consideration of the long-term consequences of their acts...[b]ecause crime transcends national boundaries, criminality does the same" (Gottfredson and Hirschi 1990, p. 177). In other words, our

\section{Footnote 6 (continued)}

Hay and Meldrum 2016). It is similar to, but distinct from, some definitions of self-regulation, or "executive functions", but it is explicitly inconsistent with the idea that self-control is an impulse or a "propensity" for crime. For a recent critique of the consequences of failing to appreciate these differences, see Gottfredson and Hirschi 2019; esp, Chaps. 2, 4). For arguments that advance the merits of the Modern Control Theory definition over these recent attempts, including the ideas of "criminality", "propensity for crime" and of "conscience", see Gottfredson and Hirschi 1990, pp. 87-88; 2019, Chap. 2). We have also argued that self-control is relatively stable over lengthy periods - a concept sometimes misunderstood or mischaracterized by critics (see, esp., Gottfredson and Hirschi 2019, Ch. 4). 
theory expects the same concept to help explain delinquency and crime in global contexts. ${ }^{7}$ To date, many researchers have found strong reason to agree and find self-control "... one of the most prominent and most researched theories of crime causation in international contemporary criminology" and to claim that "[i]n the empirical literature, low selfcontrol has been established as one of the best predictors of deviant and criminal activity" (Hirtenlehner and Kunz 2017, p. 37).

The development of strong social bonds in conjunction with strong self-control creates many life-long advantages for individuals and reduces the harms both to self and others caused by interpersonal violence, crime and victimization. And, of course, as depicted in Fig. 1, as many decades of data show, there is a fundamental, substantial relationship between age and the frequency of these harms. As is well known and validated by extensive cross-national data, the general age distribution of crime can be summarized as rising rapidly through preadolescence, peaking in late adolescence or early adulthood and then declining rapidly and then continuously throughout life (Quetelet 1842; Hirschi and Gottfredson 1983; for a recent review and connection to Modern Control Theory, see Gottfredson and Hirschi 2019, Chap. 3). For Modern Control Theory, the disciplinary-free assumption of bounded rationality is essentially the same as that employed by modern theories of opportunity in criminology (see, e.g., Clarke 2018; Gottfredson and Hirschi 2019, pp. 207-209).

Finally, our theory begins with the observation that crimes and delinquencies are events; they require for their occurrence an individual disposed to behave in ways that facilitates delinquent or criminal acts and also "targets" and "opportunities." For our general theory, both individual dispositions and suitable situations are proximate causes of crime (Gottfredson and Hirschi 1990, pp. 177-179; Gottfredson and Hirschi 2019, Chaps. 5-6). Of course, differences in self-control and in social bonds are themselves predictive of individual differences in opportunities as they are associated with daily activities and settings in which people interact, both via self-selection and informal and formal selection by others.

With these elements of our theory in mind, we can turn to several strands of contemporary cross-national research to illustrate how they are essential considerations for the theory.

\footnotetext{
${ }^{7}$ For example, Ren, Zhao, and Luo (2018) have pointed out that the concept of self-control is common to both Chinese and Western societies. They note that self-control plays a major role in Chinese society "... in that the ongoing exercise of self-control for a common cause lies at the very core of Confucian philosophy" (p. 170).
}

Advances in Measurement: Theory-Sensitive Self-report Surveys of Crime and Victimization in Cross-national Studies

The creation and refinement of surveys measuring selfreported problem behaviors and victimization, by scholars working on cross-national projects, is one of the most significant methodological advances in the study of crime and its correlates in criminology in the last half-century. These systematic, carefully developed, surveys have enhanced measurably our ability to understand the meaning of official data about crime. Even more so, they have provided a wealth of high-quality research findings from diverse settings around the world on the correlates of delinquency and crime measured in strikingly comparable ways. They have been purposefully developed to assess offending and victimization without reliance on legal definitions or particular legal codes, making them essential basic data for global criminology. Furthermore, these surveys have, from the beginning, been developed in accordance with careful methodological assessments. From individual studies that use surveys to test theories of crime in one or more countries at a time, to the international victimization and self-report surveys that measure common variables with common instruments, these studies provide essential tools for criminology, tools that have, as a substantive matter, advanced the role of cross-national data to the status of foundational knowledge (examples include, Enzmann et al. 2018; Gruszczyaska et al. 2012; Junger-Tas et al. 2012; Marshall et al. 2020; and Van Dijk et al. 1989).

Certainly, challenges of measurement and of sampling remain significant and interesting research areas of their own right and there are ample reasons to be concerned about the comparative validity of the absolute levels of crime and victimization described in these surveys (for analyses of this issue, see Enzmann et al. 2018; Marshall and Enzmann 2012; Marshall and Maljevic 2013). They also have revealed important cultural differences of considerable significance, for example, the documentation of some differences in responses to confidentiality and in reporting interpersonal violence (Enzmann et al. 2018). Taken together, however, results of these efforts to measure and study offending and victimization by survey methods internationally have produced data with significant implications for how we know about and understand the meaning of major facts about crime and delinquency, in international context. Simply put, global criminology has developed a body of research findings that theoretical criminology cannot ignore.

One methodological decision in the design of these surveys critical to enhancing cross-national study (and critical to Modern Control Theory) was the very definition and subsequent measurement of the dependent variable. As 
Marshall et al. (2020, p. 36) observe, "self-report surveys measure offending by using common sense, incident-based behavioral descriptions of offenses, rather than legal definitions. This feature allows comparisons among groups with different legal systems, which is of paramount importance for cross-national comparisons of offending and victimization among young teens." This innovation (also pioneered in early cross-national victimization surveys, e.g., Van Dijk et al. 1989), allows flexibility in the creation of dependent variables and strips them from the traditional, narrow focus on legal or moral acts and substitutes instead a focus on harms. As such, this method facilitates connections among otherwise seemingly widely disparate problem behaviors and enables comparisons among groups with differing legal or cultural ideas of delinquency and crime, both within and between societies.

These international self-report surveys document fundamental facts about interpersonal crime and violence, delinquency and victimization that transcend specific societies. Just a few examples: they underscore the important role of parents, schools, age, gender and peers everywhere; they reinforce the image of versatility of problem behaviors, of the victimization/offending connection, and the importance of settings in which delinquency tends to more frequently occur (all consistent with Modern Control Theory). At the same time, the many systematic reviews of empirical work, both cross-national and individually within many countries, from a variety of behavioral science disciplines, very consistently support the inference that self-control is a substantial, general cause of crime, victimization and related problem behaviors (e.g., Baumeister and Heatherton 1996; Botchkovara et al. 2015; Chen 2009; Cho 2017; Cho and Wooldredge 2016, 2018; Cunha and Heckman 2007; de Ridder et al. 2012; Duckworth 2011; Engel 2012; Gottfredson 2018b; Gottfredson and Hirschi 2019; Hirtenlehner and Kunz 2017; Junger and Dekovic 2003; Kim et al. 2018; Kobayashi et al. 2010; Lu et al. 2012; Moffitt et al. 2011, 2013; Nofziger 2009; Pauwels and Svensson 2011; Posick 2013; Pratt 2016; Pratt and Cullen 2000; Pratt and Turanovic 2016; Pratt et al. 2014; Rebellion et al. 2008; Ren et al. 2018; Schulz 2006; Schreck 1999; Serrano Maillo 2013; Serrano Maillo and Birkbeck 2013; Tangney et al. 2004; Vazsonyi et al. 2001, 2004, 2015, 2017, 2018; Weng and Chui 2018). The recent meta-analytic study by Vazsonyi et al. (2017) includes studies published between 2000 and 2010. They conclude that the results.

... provided strong and convincing evidence, based on about 100 cross-sectional and longitudinal studies, that a strong link between low self-control and deviance or crime exists and that it does not greatly vary across modes of assessment, across study designs (cross-sectional versus longitudinal), across measures of deviance, across different populations within the United States, but also across samples across cultures" (Vazsonyi et al. 2017, p. 30, emphasis added).

Similarly, Marshall et al. (2020, p. 76, citations omitted) report that self-control “...has demonstrated its conceptual validity in diverse cultural contexts ranging from Argentina to Saudi Arabia and China and its predictive utility in relation to a range of offending behaviors, from cyberbullying to credit card fraud and victimization. Thus, low self-control has been firmly established as a relevant causal variable in criminology, whether modeled separately or as part of crime propensity".

The high-quality, cross-national ISRD self-report studies show additional strong cross-national similarities in other correlates as well, including gender and age effects, and " ...in all participating countries, adolescents with strong and positive links to school and family, with law-abiding friends, living in well-integrated neighborhoods and with high selfcontrol are most likely to report low levels of delinquent behavior" (Marshall et al. 2020, pp. 36-37). They also reveal that the relations between victimization and offending, peers, school attendance, neighborhood organization, parental bonding and self-control are similar (Marshall et al. 2020, p. 41). Such cross-national consistency in correlates for offending and victimization are findings consistent with Modern Control Theory, findings that no putative general theory of crime and victimization should be allowed to ignore.

\section{Cross-national Trends in Crime and Violence}

Another noteworthy contribution of cross-national research in criminology pertinent to and consistent with the expectations of Modern Control Theory are empirical studies of national crime trends. These studies tend to show remarkable consistency in these trends of crime and interpersonal violence in a wide range of settings, studies that also fundamentally challenges the role of state sanctions in producing substantial crime-effects. At the same time, much of this research supports the role of prevention, centered both on early childhood circumstances and on situational prevention techniques. Beyond question, cross-national research has played a very significant role in contemporary (and historical) explanations for national-level trends in interpersonal violence, crime and victimization. In fact, the cross-national research on this topic could well stand as a text-book example of the hazards of explanations of criminology that rest on provincial, single-nation considerations for explanations of crime (e.g., Blumstein and Wallman 2005). Cross-national studies of crime-rate trends have demonstrated that the early "crime drop" studies, with their focus on U.S.-centric 
policies, practices, and aspects of crime, left out two major facts: (1) the similarity of trends among very many other countries in many forms of problem behaviors; and (2) the substantial crime rise in the preceding period. Perhaps these oversights were due to the steadfast focus in the U.S. on the putative effects of the criminal justice system, particularly deterrence and incapacitation. In any event, because not all countries experience the massive criminal justice responses to the initial rate increases during this period, there was not the preexisting view everywhere that they should somehow be responsible for the "crime drop". 8

Advances from cross-national scholars in the study of crime trends have been made on both empirical and theoretical levels, both with respect to modern trends and historical periods. This is a vast and active literature and, given large changes in routine and not-so-routine activity patterns currently being experienced, crime-rate changes will continue to be a rich and vital source of data for cross-national criminology. For present purposes we can focus on examples of two significant findings from cross-national studies in this area and one theoretical inference: (1) the generality of trends, including interpersonal violence, other crimes, and other problem behaviors and their commonality across places; (2) the lack of substantial effects found for variations in criminal justice sanction practices and policies for accounting for these trends across societies; and (3) the strong likelihood that trends in individual and group levels of Modern Control Theory factors (perhaps especially selfcontrol and age effects, along with situational opportunity variables) can help account for both modern trends and substantial historical patterns. ${ }^{9}$

Tonry (2014, p. 1) provides a comprehensive and detailed summary, along with a sophisticated analysis of the international trend data, noting that crime rates have moved in parallel in Western societies (since the late Middle Ages) and, in the recent modern data, rates nearly everywhere have mostly fallen, considerably. These trends are shown in both police and victimization data. On the basis of the research, he concludes that "Most agree that, whatever the explanations may be, they do not include direct effects of changes in policing or sanctioning policies" $(2014$, p. 1). In addition, "All Western countries (and many others) appear to march to the same distant drummers without realizing that is what they are doing and that ....many of the things that governments have done to reduce crime rates in recent decades have been largely epiphenomenal-normatively and politically important, and having major effects on many people's lives, but pretty much beside the point in terms of crime rates and patterns" (Tonry 2014, p. 3).

Recent work by Eisner et al. (2016) show that trends in interpersonal violence are similar for different types of violence and are also similar for property crime, teenage pregnancy rates, and alcohol use, smoking, and the use of illicit drugs other than cannabis among adolescents (see also, Mishra and Lalumière 2009). Although they report that local or national policy decisions do matter, the underlying consistency in trends despite variability in policy and practice suggests strongly that ".... some broad underlying factor has shaped the shared trend across high-income countries" (2016, p. 71).

On the situational opportunity front, cross-national studies provide evidence of effects for what may be considered situational prevention methods (Clarke 2018) ${ }^{10}$ For example, Farrell et al. (2014) present data and arguments that the recent international fall in crime may well be significantly a consequence of widespread use of modern prevention methods that disrupt the opportunity for crime. ${ }^{11}$

With respect to age effects on crime rates, recent empirical work indicates that the role of age is quite general crossnationally. Santos et al., noting that "... age has been established as one of the best predictors of deviant and criminal activity" (2019, p. 37), provide an extensive homicide date set that shows that many countries have experienced the substantial declines in homicide rates over the modern period. Unlike many prior studies, however, they are able to show that age structure is associated with the international homicide trends since the 1960s, which of course includes both the increase and then the large decline in these rates in recent decades. The generality of the effect, leads them away from explanations centered on domestic policies and social events within individual countries (similar to Tonry 2014) to a broader global phenomenon; in the end, they argue that changes in country-level age structure is a "key factor" in understanding global homicide trends over the past six decades. ${ }^{12}$

\footnotetext{
${ }^{8}$ For general critiques of the fascination in the U.S. to the potential deterrent and incapacitative prospects for the criminal justice system, see Gottfredson and Hirschi $(2016,2019)$ and Tonry (2015).

9 Admittedly, these are large topics and involve a large literature that can only be mentioned here-for general arguments, see, e.g., Eisner (2001, 2014), Farrell et al. (2014), Mishra and Lalumière (2009), Santos et al. (2019), Tonry (2014), and Gottfredson and Hirschi (2019, Part II).
}

\footnotetext{
$\overline{10}$ For connections between situational prevention notions and opportunity to control theory, see Gottfredson and Hirschi (2019, Ch. 6).

11 But compare Tonry (2014, p. 52).

12 Exceptions to the pattern include countries with substantial, "drugwars" with associated homicide events. Such major national phenomena may well overwhelm the causes for trends in interpersonal crime and violence more generally.
} 


\section{Lack of Effects for Criminal Justice Sanctioning Policies but Significant Effects for Prevention Focused on Childhood Environments and Situational Prevention}

In describing Modern Control Theory, we have for some time argued that a focus on early childhood environments, the family, and situational opportunities provide clear public policy alternatives to policies focused on policing and incarceration by the state justice systems (Gottfredson and Hirschi 1990, 1995, 2016, 2019). Although beyond the scope of this essay, a large body of research in the U.S., both on the effects of criminal sanctions on crime rates and on the benefits of enhancements of early childhood environments for reduction of problem behaviors, largely confirms these inferences (see, e.g., Gottfredson and Hirschi 2016, 2019, Chaps. 7, 11; Gottfredson 2013; see also Heckman 2006, 2007). The development of self-control relatively early in life is predictive of less delinquency, less involvement in the juvenile and criminal justice systems, better success in school, higher wages, better health outcomes, and more stable interpersonal relationships. At the same time, research strongly suggests that variation in criminal justice sanctions, especially variation in their severity, have little impact on crime and carry substantial negative collateral consequences (National Research Council 2014; Pratt 2009; Pratt et al. 2006).

Considerable consistency with these views has been provided by cross-national research, a consistency that cannot be ignored by scientific criminology. The relative lack of credible evidence finding that variations in criminal justice sanctions substantially cause the level of crime and violence in a society and the growing consensus about evidence supporting the benefits of prevention strategies for the reduction of levels of interpersonal violence and crime transcend national boundaries (see, e.g., Eisner et al. 2016, Gottfredson and Hirschi 2019, Chaps. 7-11; Tonry 2015; von Hirsch et al. 1999; Tonry 2014). As Tonry (2014) reports based on an appreciation of the cross-national data, the penal policies and punishment systems of different societies are likely the products of their own distinctive national histories and cultures... but they have little or no effect of crime rates. Something else is responsible for the changes over time. Eisner and colleagues put it this way:

[The data] suggest a common factor or some factors that has/have affected the common underlying trend across space and between behavior domains. This corresponds to findings at the individual level where research indicates high comorbidity across developmental psychopathologies, a lack of offender specialization, and the subordinate role of domain-specific risk factors. Unfortunately, researchers do not at present fully understand the nature of these possible common causes. One hypothesis is a broad cultural shift in much of the afflu- ent Western world toward increasing emphasis on selfcontrol and a heightened moral proscription of behaviors that harm others. Overall, these findings underline the significance of prevention programming that broadly supports a healthy child and youth development rather than focusing overly on specific subtypes of violence (Eisner et al. 2016, p. 71).

\section{Conclusion}

From its beginnings in the classical school, theoretical criminology has always been an international discipline. The sophistication and vast international body of research contributions over many decades means also that empirical criminology is an international discipline. The innovations in survey research, including the development of measures of crime and related harms that do not depend on legal definitions, but which are present in all cultures and legal systems, has made possible scientifically appropriate measures for global criminology. The use of these survey methods, stemming from both self-reported offenses and victimization have provided the field with indicators that demonstrate remarkable consistency. The emerging consensus that variations in within-country criminal justice sanctions are not strong causes of crime-rate differences add substantial evidence that variation in informal social controls and development of self-control are important causes of interpersonal crimes and violence. Evidence about prevention methods, focusing on early childhood and on situational effects, also deriving from cross-national work, lend important evidence to core elements of Modern Control Theory. Taken together, and apart from the many contributions that cross-national criminology has made regarding comparative criminal justice systems and practices, these contributions show clearly that the basic science of criminology can little afford to be anything less than a global enterprise.

Funding Not applicable.

\section{Compliance with Ethical Standards}

Conflict of interest The authors declare that they have no conflict of interest.

Open Access This article is licensed under a Creative Commons Attribution 4.0 International License, which permits use, sharing, adaptation, distribution and reproduction in any medium or format, as long as you give appropriate credit to the original author(s) and the source, provide a link to the Creative Commons licence, and indicate if changes were made. The images or other third party material in this article are included in the article's Creative Commons licence, unless indicated otherwise in a credit line to the material. If material is not included in the article's Creative Commons licence and your intended use is not permitted by statutory regulation or exceeds the permitted use, you will 
need to obtain permission directly from the copyright holder. To view a copy of this licence, visit http://creativecommons.org/licenses/by/4.0/.

\section{References}

Agnew, R. (2015). Using general strain theory to explain crime in Asian societies. Asian Journal of Criminology, 10, 131-147.

Baumeister, R. F., \& Heatherton, T. F. (1996). Self-regulation failure: An overview. Psychological Inquiry, 7(1), 1-15.

Beccaria, C. (1764; 1995). On crimes and punishments. Cambridge: Cambridge University Press.

Bennett, R. (1980). Constructing cross-cultural theories in criminology: Application of the generative approach. Criminology, 18(2), 252-328.

Bennett, R. (2004). Comparative criminology and criminal justice research: The state of our knowledge. Justice Quarterly, 2(1), $1-21$.

Bentham, J. (1798). An introduction to principles of morals and legislation. London: Athlone Press.

Blumstein, A., \& Wallman, J. (2005). The crime drop in America. New York: Cambridge University Press.

Botchkovara, E., Marshall, I., Rocque, M., \& Posick, C. (2015). The importance of parenting in the development of self-control in boys and girls: Results from a multinational study of youth. Journal of Criminal Justice, 43(2), 133-141.

Burt, C., Simons, R., \& Simons, L. (2006). A longitudinal test of the effects of parenting and the stability of self-control: Negative evidence for the general theory of crime. Criminology, 44(2), 353-396.

Chen, X. (2009). The link between juvenile offending and victimization: The influence of risky lifestyles, social bonding, and individual characteristics. Youth Violence and Juvenile Justice, 7, 119-135.

Cho, S. (2017). Self-control and risky lifestyles in context: Cross-level integration between opportunity and collective efficacy in the study of peer victimization among South Korean youth. Journal of Child and Family Studies, 26, 67-79.

Cho, S., \& Wooldredge, J. (2016). The link between juvenile offending and victimization: Sources of change over time in bullying victimization risk among South Korean adolescents. Children and Youth Services Review, 71, 119-129.

Cho, S., \& J. Wooldredge. 2018. Direct and indirect effects of low self-control on the personal victimization of South Korean youth. Journal of Youth Studies, 1-25.

Clarke, R. (2018). Situational crime prevention. Oxford research encyclopedia of criminology and criminal justice. New York: Oxford University Press.

Cunha, F., \& Heckman, J. (2007). The technology of skill formation. American Economic Review, 97(2), 31-47.

de Ridder, D., Lensvelt-Mulders, G., Finkenauer, C., Stok, F., \& Baumeister, R. (2012). Taking stock of self-control: A meta-analysis of how trait self-control relates to a wide range of behaviors. Personality and Social Psychology Review, 16(1), 76-99.

Duckworth, A. L. (2011). The significance of self-control. Proceedings of the National Academy of Sciences, 108(7), 2639-2640.

Eisner, M. (2001). Modernization, self-control and lethal violence: The long-term dynamics of European homicide rates in theoretical perspective. British Journal of Criminology, 41, 618-638.

Eisner, M. (2014). From swords to words: Does macro-level change in self-control predict long-term variation in levels of homicide? Crime and Justice, 43, 65-134.

Eisner, M., Nivette, A., Murray, A., \& Krish, M. (2016). Achieving population-level violence declines: Implications of the international crime drop for prevention programming. Journal of Public Health Policy, 37, 66-80.
Engel, C. (2012). Low self-control as a source of crime: A meta-study. Bonn: Max Planck Institute for Research on Collective Goods.

Enzmann, D., Kivivuori, J., Marshall, I., Steketee, M., Hough, M., \& Killias, M. (2018). A global perspective on young people as offenders and victims. First results from the ISRD3 study. New York: Springer.

Farrell, G., Tilley, N., \& Tseloni, A. (2014). "Why the crime drop?" Crime and Justice, 43: 421-490, 43: 421-490. Chicago: University of Chicago Press.

Gottfredson, M. (2011). Some advantages of a crime-free criminology. In M. Bosworth \& C. Hoyle (Eds.), What is criminology? (pp. 35-48). Oxford: Oxford University Press.

Gottfredson, M. (2013). A note on the role of basic theory in thinking about crime prevention. European Journal of Criminal Policy and Research, 19(2), 91-97.

Gottfredson, M. (2018a). General theory and global criminology: Childhood environments, problem behaviors, and a focus on prevention. Asian Journal of Criminology, 13, 347-365.

Gottfredson, M. (2018b). Self-control theory and crime-Oxford research encyclopedia of criminology and criminal justice. Retrieved from: http://criminology.oxfordre.com/view/10.1093/acrefore/9780190264 079.001.0001/acrefore-9780190264079-e-252.

Gottfredson, M. (2021, forthcoming). Modern control theory, lifestyle, and criminal victimization. In T. Pratt \& J. Turanovic (eds). Revitalizing victimization theory: Revisions, applications, and new directions-Advances in criminological theory. New York: Routledge.

Gottfredson, M., \& Hirschi, T. (1990). A general theory of crime. Stanford, CA: Stanford University Press.

Gottfredson, M., \& Hirschi, T. (1995). National Crime Policy. Society, 32(2), 30-36.

Gottfredson, M., \& Hirschi, T. (2016). The criminal career perspective as an explanation of crime and a guide to crime control policy: The view from general theories of crime. Journal of Research in Crime and Delinquency, 53(3), 406-419.

Gottfredson, M., \& Hirschi, T. (2019). Modern control theory and the limits of criminal justice. New York: Oxford University Press.

Gruszczyaska, B., Lucia, S., \& Killias, M. (2012). Juvenile Victimization from an International Perspective. In J. Junger-Tas, I. Marshall, D. Enzmann, M. Killias, \& M. Gruszczyaska (Eds.), The many faces of youth crime: Contrasting theoretical perspectives on juvenile delinquency across countries and cultures (pp. 95-116). New York: Springer.

Hay, C., \& Meldrum, R. (2016). Self control and crime over the life course. Los Angeles: Sage.

Heckman, J. (2006). Skill formation and the economics of investing in disadvantaged children. Science, 312(5782), 1900-1902.

Heckman, J. (2007). The economics, technology, and neuroscience of human capability formation. Proceedings of the National Academy of Sciences, 104(33), 13250-13255.

Hirschi, T., \& Gottfredson, M. (1983). Age and the explanation of crime. American Journal of Society, 89(3), 552-584.

Hirtenlehner, H., \& Kunz, F. (2017). Can self-control theory explain offending in late adulthood? Evidence from Germany. Journal of Criminal Justice, 48, 37-47.

Huff, C. R., \& Killias, M. (2013). Wrongful convictions and miscarriages of justice: Causes and remedies in North American and European criminal justice systems. New York: Routledge.

Junger, M., \& Dekovic, M. (2003). Crime as risk-taking: Co-occurrence of delinquent behavior, health endangering behaviors and problem behaviors". In C. Britt \& M. Gottfredson (Eds.), Control theories of crime and delinquency (pp. 213-241). New Brunswick, NJ: Transaction Publishers.

Junger-Tas, I., Marshall, D., Enzmann, M. K., Steketee, M., \& Gruszczynska, B. (2012). The many faces of youth crime: Contrasting 
theoretical perspectives on juvenile delinquency across countries and cultures. New York: Springer.

Kim, H., J. Min, K. Min, T. Lee \& S. Yoo. (2018). Relationship among family environment, self-control, friendship quality, and adolescents' smartphone addiction in South Korea: Findings from nationwide data. Retrieved July 1, 2008, from, https://doi. org/10.1371/journal.pone.0190896.

Kobayashi, E., Vazsonyi, A., Chen, P., \& Sharp. , S. (2010). A culturally nuanced test of Gottfredson and Hirschi's "general theory": Dimensionality and generalizability in Japan and in the US. International Criminal Justice Review, 20(2), 112-131.

Liu, J. (2009). Asian criminology-Challenges, opportunities and directions. Asian Journal of Criminology, 4, 1-9.

Lu, Y., Yu, Y., Ren, L., \& Marshall, I. (2012). Exploring the utility of self-control theory for risky behavior and minor delinquency among Chinese adolescents. Journal of Contemporary Criminal Justice, 29(1), 32-52.

Marshall, I., \& Enzmann, D., et al. (2012). Methodology and design of the ISRD-2 study. In J. Junger-Tas (Ed.), The many faces of youth crime (pp. 21-61). New York: Springer.

Marshall, I., \& Maljevic, A. (2013). Theoretical and methodological insights from the second international self-report study of delinquency (ISRD-2). Journal of Contemporary Criminal Justice, 29(2), 4-12.

Marshall, I., C. Birkbeck, D. Enzmann, J. Kivivuori, A. Markina \& M. Steketee. (2020). International Self-Report Delinquency (ISRD4) Internal Study Protocol: background, methodology and mandatory items for the 2021/2022 survey. Internal version 1.0. Boston: ISRD technical report \#4.

Messner, S. (2015). When West Meets East: Generalizing theory and expanding the conceptual toolkit of criminology. Asian Journal of Criminology, 10, 117-129.

Mishra, S., \& Lalumière, M. (2009). Is the crime drop of the 1990s in Canada and the USA associated with a general decline in risky and health-related behavior? Social Science \& Medicine, 68, 39-48.

Moffitt, T., Arseneault, L., Belsky, D., Dickson, N., Hancox, R., Harrington, H., et al. (2011). A gradient of childhood self-control predicts health, wealth, and public safety. Proceedings of the National Academy of Science, 108(7), 2693-2698.

Moffitt, T., Poulton, R., \& Caspi, A. (2013). Lifelong impact of early self-control. American Scientist, 101(5), 352-359.

National Research Council. (2014). The growth of incarceration in the United States. National Academy of Sciences. Retrieved from https ://www.nap.edu/read/18613.

Nofziger, S. (2009). Victimization and the general theory of crime. Violence and Victims, 24(3), 337-350.

Paternoster, R., \& Fisher, D. (2018). The foundation and re-emergence of classical thought in criminological theory: A brief philosophical history. In R. Triplett (Ed.), Wiley Handbook of the History and Philosophy of Criminology (1st ed.). New York: Wiley.

Pauwels, L., \& Svensson, R. (2011). Exploring the relationship between offending and victimization: What is the role of risky lifestyles and low self-control? A test in two urban samples. European Journal of Criminal Policy and Research, 17, 163-177.

Posick, C. (2013). The overlap between offending and victimization among adolescents: Results from the second international selfreport delinquency study. Journal of Contemporary Criminal Justice, 29, 106-124.

Pratt, T. C. (2009). Addicted to incarceration: Corrections policy and the politics of misinformation in the United States. Thousand Oaks, CA: Sage.

Pratt, T. (2016). A self-control/life-course theory of criminal behavior. European Journal of Criminology, 13, 129-146.

Pratt, T. C., \& Cullen, F. T. (2000). The empirical status of Gottfredson and Hirschi's general theory of crime: A meta-analysis. Criminology, 38(3), 931-964.
Pratt, T., \& Turanovic, J. (2016). Lifestyle and routine activity theories revisited: The importance of 'risk' to the study of victimization". Victims and Offenders, 11, 335-354.

Pratt, T., Cullen, F., Blevins, K., Daikgle, L., \& Madensen, T. (2006). The empirical status of deterrence theory: A meta-analysis. In F. T. Cullen, J. P. Wright, \& K. R. Blevins (Eds.), Taking stock: The empirical status of theories in criminology (Vol. 15, pp. 367-396). New Brunswick, NJ: Transaction.

Pratt, T., Turanovic, J., Fox, K., \& Wright, K. (2014). Self-Control and victimization: A meta-analysis. Criminology, 52, 87-116.

Quetelet, L.(A). 1842; 1969. A treatise on man and the development of his faculties. Solomon Diamond, Trans. Gainesville, FL: Scholars' Facsimiles \& Reprints.

Rebellion, C., Straus, M., \& Medeiros, R. (2008). Self-Control in global perspective: An empirical assessment of Gottfredson and Hirschi's General Theory within and across 32 national settings. European Journal of Criminology, 5(3), 331-362.

Ren, L., Zhao, J., \& Luo, Y. (2018). Testing the dimensionality of low self-control across three groups of Chinese adolescents. Journal of Contemporary Criminal Justice, 34(2), 168-195.

Sampson, R. (2015). Crime and the Life Course in a Changing World: Insights from Chicago and Implications for Global Criminology. Asian Journal of Criminology, 10, 277-286.

Santos, M., Testa, A., \& L., Porter, and J. Lynch. . (2019). The contribution of age structure to the international homicide decline. PLoS ONE. https://doi.org/10.1371/journal.pone.0222996.

Schreck, C. (1999). Criminal victimization and low self-control: An extension and test of a general theory of crime. Justice Quarterly, $16,633-654$.

Schulz, S. (2006). Beyond self-control: Analysis and critique of Gottfredson and Hirschi's general theory of crime. Berlin, Germany: Duncker \& Hirbult.

Serrano Maillo, A. (2013). El problema de las contingencias en la teoria del autocontrol: Un test de la teoria general del delito. 2. Edicion. Dykinson.

Serrano Maillo, A. and Birkbeck, C. eds. (2013). La generalidad de la teoria del auto control. Dykinson.

Tangney, J. R., \& Baumeister \& A. Boone. . (2004). High self-control predicts good adjustment, less pathology, better grades, and interpersonal success. Journal of Personality, 72(2), 271-324.

Tonry, M. 2014. Why crime rates are falling throughout the western world. Crime \& Justice, 43: 1. https://scholarship.law.umn.edu/ faculty_articles $/ 511$.

Tonry, M. (2015). Is cross-national and comparative research on the criminal justice system useful? European Journal of Criminology, 12(4), 505-516.

Valasik, M. (2014). Classical criminology. In J. S. Albanese (Ed.), The Encyclopedia of criminology and criminal justice (1st ed.). New York: Wiley.

Van Dijk, J., Mayhew, P., \& Killias, M. (1989). Experiences of Crime across the World: Key findings from the 1989 International Crime Survey. Boston: Kluwer.

Vazsonyi, A. T. (2003). Comparative criminology: content or simply methodology. In C. Britt \& M. Gottfredson (Eds.), Control theories of crime and delinquency. Advances in criminological theory (pp. 179-212). Transaction: New Brunswick, NJ.

Vazsonyi, A., Pickering, L., Junger, M., \& Hessing, D. (2001). An empirical test of a general theory of crime: A four-nation comparative study of self-control and the prediction of deviance. Journal of Research in Crime and Delinquency, 38(2), 91-131.

Vazsonyi, A., Wittekind, J., Belliston, L., \& Van Loh, T. (2004). Extending the general theory of crime to "the east:" Low selfcontrol in Japanese late adolescents. Journal of Quantitative Criminology, 20(3), 189-216. 
Vazsonyi, A., Mikuska, J., \& Kelley, E. (2017). It's time: A metaanalysis on the self-control-deviance link. Journal of Criminal Justice, 48, 48-63.

Vazsonyi, A., Javakhishvili, M., \& Ksinan, A. (2018). Routine activities and adolescent deviance across 28 cultures. Journal of Criminal Justice, 57, 56-66.

Vazsonyi, A. T., Roberts, J. W., Huang, L., \& Vaughn, M. G. (2015). Why focusing on nurture made and still makes sense: The biosocial development of self-control. In The Routledge International Handbook of Biosocial Criminology (pp. 263-280).

von Hirsch, A., \& BottomsBurneyWikström, A.E.P.-O. (1999). Criminal deterrence and sentence severity: An analysis of recent research. Oxford: Hart Publishing.
Weng, X., \& Chui, W. (2018). Assessing two measurements of selfcontrol for Juvenile delinquency in China. Journal of Contemporary Criminal Justice, 34(2), 148-167.

Wikström, P.-O., Oberwittler, D., Treiber, K., \& Hardie, B. (2012). Breaking rules: The social and situational dynamics of young people's urban crime. Oxford: Oxford University Press.

Wikström, P., Mann, R., \& Hardie, B. (2018). Young people's differential vulnerability to criminogenic exposure: Bridging the gap between people- and place-oriented approaches in the study of crime causation. European Journal of Criminology, 15(1), 10-31. 